\title{
Performative Understanding of Architecture
}

\author{
Marat Nevlyutov \\ Scientific Research Institute of Theory and History of Architecture and Urban Planning \\ Central Institute for Research and Design of the Ministry of Construction, Housing and Communal Services of the Russian \\ Federation \\ Moscow, Russia \\ mnevlyutov@gmail.com
}

\begin{abstract}
Traditional notions of architecture as something coherent specific and complete collapse. Theory of architecture shifts its focus from an object to an action, from a text to a performance. A performative understanding of architecture allows us to describe the building or environment as a movement, a change in time, a becoming. The notion of performativity in contemporary theory of architecture radically changes the thinking of architect and design methods.
\end{abstract}

Keywords-phenomenology of architecture; performativity; duration; action; time; weathering; natural forces; resistance; fracture; surface; event

\section{INTRODUCTION}

Today we can observe that attention to the phenomenon of "performativity" in contemporary theory of architecture is growing. It can be explained by the inadequacy of existing positions, based on the primacy of the text, the sign and communication. A performative understanding of architecture allows us to describe the building or environment as a movement, a change in time, a becoming. It was always known, that architecture exists in time: any building has to grow old and finally be destroyed by its own environment. But this fact was mostly perceived as an unwanted, accidental consequence and ignored persistently. The modern trend is that architecture is committed to embrace the time and the environment as a fundamental base for its activity, thereby asserting its performative nature.

\section{PERFORMATIVITY}

The concept of performativity comes not from an architectural tradition, but from a linguistic one. This term was introduced by John L. Austin in his lectures on the philosophy of language "How to do things with words" that he has read at Harvard University in 1955. The scientist said that the use of performative utterance or a performative "... is not to describe my doing of what I should be said in so uttering to be doing or to state that I am doing it: it is to do it" [1]. Performativity refers to that kind of expressions that do not simply describe reality, but assert it and create what they talk about being "self-referential". Austin did not invent anything; he just reminded that language has the power to produce changes in the reality.

For a long time the concept of performativity was not widespread outside of discussions on linguistics and philosophy of language, but later it detects its explanatory advantages in other areas of culture. It has happened when weaknesses of the understanding of the culture as a text, which had prevailed since the mid-20th century until the late 80 's, became obvious. The famous theatre researcher Erika Fischer-Lichte points at the "performative revolution" that took place in art in the late 20th century. The scientist introduces the term "performativity" as opposed to "textuality" to the theater studies. Fischer-Lichte writes, "Cultural studies increasingly employed this independent (practical) frame of reference for the analysis of existing or potential realities and acknowledged the specific "realness" of cultural activities and events, which lay beyond the grasp of traditional text models. This gave rise to the notion of "culture as performance"" [2].

An increased attention to the performativity of culture arises due to the crisis of rationality, which was reflected in the late 19th century in some of the philosophical systems: phenomenology, philosophy of life, psychoanalysis. At the same time, attempts to rethink the time - the main subject of performativity - have been made. According to Henri Bergson, time is slipping away from an understanding of mathematics and natural sciences, for the reason that they are products of the intellect and thus have the ability to perceive only what is stationary: "If, therefore, the tendency of the intellect is to fabricate, we may expect to find that whatever is fluid in the real will escape it in part, and whatever is life in the living will escape it altogether" [3]. Bergson insists that the world is constantly changing in time, and we are only able to grab the fixed states - the time slices. Instead of the intellect, the philosopher suggests an intuition, which can give a different perspective to the reality as duration, a movement. The performativity can be problematic for intellectual understanding, for the reason that it requires to get rid of exteriority of mathematical time and to observe things from within time, in their own becoming.

The notion of performativity enters the architectural field in the 80-ies in connection with a wide criticism of the "deadness" of modernism. Its theoretical and philosophical aspects were described by Dalibor Veseli, David Leatherbarrow, Mohsen Mostafavi, Branko Kolarevic. The technological aspect of a transformation of a building is considered by such researchers as: Mahadev Raman, Andrew Valey, Ali Malkawi, Thomas Herzog. Among the architects some aspects of the performativity are highlighted by Peter 
Zumthor, Jacques Herzog, Pierre de Meuron. Jean Nouvel and Paul Virilio talk about the architecture existing in the context of urban transformation. In this text I will follow my phenomenological line [4], which has been most fully developed by David Leatherbarrow, in some cases in collaboration with Mohsen Mostafavi.

\section{III. "HOW" IS THE ARCHITECTURE}

David Letherbarrow begins with determining two ways of understanding architecture that prevailed in the postwar period: the building as the system of functional elements implemented in the construction and the building as a representation of composite solutions that exist in the experience of personal perception. Both ways of understanding percieved the building as an object: first saw the architecture as a result of technical conditionality, the second - an assertion of aesthetic expectations for construction. The theorist describes this disposition of aesthetic and technological architecture as irrelevant, and debates about the choice between beauty and usefulness pointless.

In contrast to the existing understanding, Letherbarrow replaces the question "what" is architecture (aesthetic or technological object) to the question "how" is the architecture: "This inquiry's central question can be stated simply: in what ways does the building act? What, in other words, does the architectural work actually do?" [5]. Thus, the theorist claims the shift of architectural theory and practice from what the building is, to what it does, in other words from an essence to an existence, from a text to a performance. At a glance it seems that the concept of performativity cannot be applied to the architecture as it remains in close relationships with performative artistic practices. Indeed, unlike music, theater and dance, architecture does not act towards the audience, and is perceived as a background for the action. However, the architecture is also located in time, and therefore should be disclosed in the acts of its existence. Furthermore, Letherbarrow considers the theme of performativity to be not just possible, but the only one capable of revealing the ontological meanings of architecture.

In his notes Letherbarrow distinguishes two kinds of architectural performative: "The first sort is technical and productive, the second, contextual and projective" [6]. The first involves the literal movements and changes in architecture: kinetic mechanisms, the replaceable elements and fittings. Each of these elements has a certain range of movement, which allows them to change their position and location in space. He connects this performativity to the "paradigm of devices" [7]. The second type reflects unplanned, living process of construction and maintenance carried out in time and in a particular place. Letherbarrow says, "For a theory of performativity, we should seek nothing more and nothing less: instrumental reason and the rationality on which it depends, plus situated understanding that discovers in the particulars of a place, people, and purpose the unfounded conditions that actually prompt, animate, and conclude a building's performances" [8]. The theorist focuses on the second type of performative as he considers the first one to be necessary technological nonconceptual addition, without its own non-technical essence.

\section{WEATHERING}

Leatherbarrow believes that in architecture, nothing is apart from the efforts and intentions that have led to its beingness and visibility. Architecture is manmade, and this fact imposes a certain effect on it that cannot be ignored. "If we feel awe before a granite wall, the sentiment that overwhelms us arises from our estimation of the labor required for the wall's construction and finishing, not from valuation of the material itself" [8]. The value of the item occurs not because of itself but the invisible reasons for its implementation: how it was made. It unites Letherbarrow with the thinkers he referred to- Adolf Loos and John Ruskin, who also sought to see traces of human hands on the architectural surface and thereby assert its value. But what is more important for Letherbarrow is not the human labor invested in the creation of things, but the duration of the external forces and impacts.

In his book, "Weathering", through examination of the projects from Alberti to Le Corbusier, Leatherbarrow shows that the constant updating, the renovation of the building, collapsing under the influence of natural forces, brings the new value and constructs and an unintended meaning, which has not initially been presented to the architecture. "Deleterious consequences can be complemented by the potential value of sedimentation and the accumulation of detritus on a surface through the action of the weather. This process always marks, and these marks may be intended, even desired" [9]. The building always contains the effects, the consequences of external influences. Letherbarrow does not focus on the human origin of the degradation of the material: the history of the building is its duration, in which active forces are impersonal.

Many architects are well aware of the positive power of weathering. Leatherbarrow mentions, as an example, architects Peter Zumthor and Carlo Scarpa, who use the influence of natural forces as a means of expression. Zumthor calls the process of aging the "enrichment" of the material. The building attains beauty and special richness when traces of life remain on its surface. The architect writes "But when I close my eyes and try to forget both these physical traces and my own first associations, what remains is a different impression, a deeper feeling - a consciousness of time passing and an awareness of the human lives that have been acted out in these places and rooms and charged them with a special aura. At these moments, architecture's aesthetic and practical values, stylistic and historical significance are of secondary importance. What matters now is only this feeling of deep melancholy. Architecture is exposed to life. If its body is sensitive enough, it can assume a quality that bears witness to the reality of past life" [10]. In his projects Scarpa uses the wall surfaces to demonstrate the existence of architecture in time as wind and water leave traces on light stone surfaces of his buildings. Thus, the "weathering" can be an element of the building provided by the architect. 
Architecture resists time, it is in a state of perpetual war with time, and this war is recorded on surfaces. Architecture is a living entity, which is always struggling with the external environment, which inevitably leads to its disappearance. The process of destruction of buildings is as inevitable as its incarnation and end of life for architecture is no less significant than the moment of its creation. Letherbarrow writes, "No doubt it is obvious to state that over time the building's materials eventually fail; but we rarely think seriously enough about this inevitable or essential contingency" [11].

In addition to the surface material, the main body of a building is a response to natural forces. The building construction is designed to resist snow, rain, heat and other climatic changes and incidents. The building is making efforts to act against the world, but always loses in the end. "There is another site of architectural action in which performance is less obvious but no less determining: those parts of the building that give it its apparently static equilibrium, its structural, thermal, material stability. When discussing these elements (columns and beams, retaining walls, and foundations, but also cladding and roofing systems), it is common to talk of their "behavior" — and not only talk of it but anticipate, even predict it. Obviously, talk of this sort is metaphorical, but in truth the building must work at staying as it is. It must work with ambient conditions, such as gravity, winds, sunlight, and so on. It must also work against these forces" [11].

Thus, the "weathering" is an evidence of the inevitable continuation of the construction process which never ends, as the problem of resistance to the circumstances of reality continually presents itself. Letherbarrow, offers an alternative understanding of the history of an individual building and architecture in general as a process of constant reproduction of architecture, not its static state in which any change is undesirable. He describes architecture as the repetition of the ritual, which gives us is a special kind of comfort in its continuity, because any change and evolution always means destruction, and the repetition of the same action gives us hope for the perpetuity of architecture.

\section{SPECIAL PlaceS}

Architecture is capable of maintaining its traces in its environment that arise due to the diversity of places, people, events taking place there. Of course, there are many circumstances that lead to the universality of architectural statements. One of such tools, reducing the world to the uniformity, is the construction technologies, which aims to improve the quality and increase quantity through the unification of production methods. However, due to the vulnerability of places to weathering, even architecture of the international style still has unintentional variations.

Architecture exists in an unpredictable world of everyday events. In a life of buildings much more happens than that an architect would suggest, and that imposes additional requirements on the functional use of architecture. Aldo Rossi noticed that the function of the building changes frequently over time and the functionality criterion that defines the shape is very unstable. The shape intended for certain kinds of activities, is preserved, but the function may not be there anymore. Rossi writes, "Similarly, architecture becomes the vehicle for an event we desire, whether or not it actually occurs; and in our desiring it, the event becomes something "progressive" in the Hegelian sense. I shall come back to this later. But it is for this reason that the dimensions of a table or a house are very important-not, as the functionalists thought, because they carry out a determined function, but because they permit other functions" [12].

Letherbarrow, along with Rossi defines architecture as a tool that allows anything to happen, as the usual scenery or a background for the diversity of human life to unfold. Architecture, thus, needs to remain invisible to be really good. Letherbarrow insists that the elements of the service should abandon the severity and visibility. "The enjoyment of a meal hardly requires steady attention to the chairs, glasses, and napkins that allow it to take place. The "service" they perform involves not only subjection and anticipation but a particular kind of recession, a retreat or withdrawal from perceptual prominence" [13]. Such "unobtrusiveness" is also a key idea of modernism ideologist Adolf Loos. It calls for "restrained" architecture, in his opinion, the house, like the furniture, should not draw excessive attention - it should express itself silently. Loos uses the term "transparency" to denote the obscurity of the building, which is set to environment. The architect Louis Kahn, as well as Loos, in detail develops a similar concept of "service" spaces. The building, in his opinion, should be developed for human existence, it should enhance and supplements the person and recede. Such recession indicates that the architecture was in helpful and obscured itself into its own usage.

Letherbarrow, believes that the building should act in accordance with its unstable environment, hiding in it, so the form should be a subject of interpretation and change. The building, which is too rigidly tuned to the environmental conditions or its usage, is not able to respond to unforeseen circumstances. Aldo Rossi also speaks on the beauty of an unintended change in architecture: "I always liked the settling of the Pantheon described in the books on statics; the unforeseen crack, the visible but contained collapse, gave immense strength to the architecture because its beauty could not have been anticipated" [14].

Reflecting on unexpected events in the life of architecture, Leatherbarrow finds topographical or urban nature of architecture. In the understanding of the theorist, it is a shift of attention to another "object of design", namely the territory, where the architectural performance takes place, a place where architecture operates [15]. Letherbarrow, criticizes international style for its distance in relation to the place: "This style was frequently described as antiurban because its prejudice in favor of freestanding objects led to the disruption of existing patterns" [16]. Such projects, according to the theorist, are non-dual, singular, strive for unambiguous, see no change, because they are out of context and time, but only in their own abstract idea, concept.

It would be not be enough to mention only the influence of the environment on architecture, because it also affects the 
environment. The architectural performative creates changes of not only spatial nature but totally changes the reality, highlights the special place where social action takes place or, simply put, life. Fischer-Lichte notes "The feast evoked a sense of community and, as ritual, was able to produce a political community. Once more, the performative acts were pivotal for the ritual in order to bring forth what they performed: the social reality of a community" [17]. The architecture allows for the implementation of the ritual for the emergence of a community united around a common political actions or events.

\section{EVENT}

The architectural performative avoids the visibility and measurability to appeal to the value of the unfolding world which is far superior than an architectural form. This service of architecture to something external to it makes it an event. This kind of service of architecture to something external makes architecture an event itself. Concealment of architecture, its dissolution in disjointed daily activities happens due to the fact that architecture has become something else, non-architectural. To describe the essence of architecture Letherbarrow also refers to categories of events, as he writes, "Events cannot be defined, organized, or scripted because their beginning, middle, and end resist objective comprehension. This leads to a first conclusion: to understand architecture's performative character, we cannot rely on transparent and objective description alone, or on techniques of quantification and measurement" [17]. An event is impossible to measure, because it lasts in time, and thus eludes intellectualization. Bergson mentioned earlier, also uses the concept of event to describe the inability of consciousness to grasp the duration. Deleuze, following Bergson in his philosophy, indicates that the event is "nontime", which is unfolded in time as a duration.

Martin Heidegger gives a slightly different value to the event. For him it is unique, and opens up a part of his implicated being. Alain Badiou is close to Heidegger in his understanding of the events, but he endows it with properties fundamentally different from being: an event for him is fundamentally different in relation to the current situation. Letherbarrow also says that the event is different in relation to the previous situation, but always comes from the past, from which it seeks to differentiate. Based on this thoughts he is able to distinguish between a simple motion of "devices" and a real architectural performative, the implementation of which is possible only through technical means. He writes, "Technique is always anticipatory; it is a form of knowledge that leads to preconceived results. Because events arise out of a past that we do not know, they cannot be produced technically" [17].

According to Leatherbarrow, architecture can be an event regardless of our assumptions or even vision of what is happening as the event is not caused by our desire or understanding. "Viewing the way an event unfolds in the present, we can discern an essential aspect of settings: placebound events that truly merit the name arise out of themselves, despite my interests or yours, as if they were indifferent to them" [17].
The event-driven success of architecture is determined by the conditions or place, which are not created by the architect and pre-given and at the same time depend on already continuing actions of the architecture. Letherbarrow writes, "Although architects are responsible for the design of spatial set-tings, the measure of their success depends on the adequacy of those settings with respect to patterns of behavior no one has designed, the situations and institutions of contemporary culture" [17]. The architect becomes responsible for the occurrence of events that don't depend on him.

\section{CONCLUSION}

The notion of performativity in contemporary theory of architecture radically changes the thinking of architect and design methods. Performativity implies a very simple thing architecture exists in time. This obvious statement drastically changes the way we think about architecture. Traditional notions of architecture as something coherent specific and complete collapse. Theory of architecture shifts its focus from an object to an action, from a text to a performance.

Design principles based on the of the performativity of architecture, imply the simultaneity of different realities: spatial, technical, social, aesthetic etc. A multitude of different layers become inextricably linked in the performative. Architectural theorist Leatherbarrow puts performativity at the centre of his attention. He interprets architecture as a political action, continuously performed in space. Architecture for him is a living entity in the process of becoming, linking together all aspects of event reality. The increased focus on the performativity of the building blurs the distinction between geometry and analysis, technique and aesthetics of the building and landscape, function and form. So the architecture absorbs the aleatoric of life, which is a crucial shift in the understanding of contemporary architecture.

\section{REFERENCES}

[1] J.L. Austin, How to do things with words. Oxford: The Clarendon Press, 1962, p. 6

[2] E. Fiscer-Lichte, The Transformative power of performance. A new aesthetics. Translated by Saskya Iris Jain. New York: Routledge, 2008 (First published 2004), p. 26.

[3] H. Bergson, Creative Evolution. New York: Palgrave Macmillan, 2007 (first published 1907 by Presses Universitaires Francaises as L'evolution creatrice), p.169

[4] M. Nevlyutov, Phenomenological concepts of the contemporary theory of architecture // Architecture and Modern Information Technologies. AMIT. 2015. №3 (32).

[5] D. Leatherbarrow, Architecture's unscripted performance // Performative architecture :; Beyond instrumentality / Branko Kolarevic and Ali Malkawi. New York: Spon Press, 2005, p. 8.

[6] D. Leatherbarrow, Architecture Oriented Otherwise. New York: Princeton Architectural Press, 2009, p. 63.

[7] D. Leatherbarrow, Architecture's unscripted, p. 12.

[8] D. Leatherbarrow, Architecture Oriented Otherwise.

[9] D. Leatherbarrow, On Weathering: The Life of Buildings in Time, with Mohsen Mostafavi . Cambridge, Mass.: MIT Press, 1993, p. 4.

[10] P. Zumthor, Thinking Architecture. Basel: Birkhauser, 1999, p. 24. 
[11] D. Leatherbarrow, Architecture Oriented Otherwise, p. 56.

[12] A. Rossi, A scientific autobiography. The MIT Press: Cambridge, London, 1981.p.3

[13] D. Leatherbarrow, Architecture Oriented Otherwise, p. 123.

[14] A. Rossi, A scientific autobiography, p. 15.

[15] D. Leatherbarrow, Architecture Oriented Otherwise, p. 110.

[16] E. Fiscer-Lichte, The Transformative power of performance. A new aesthetics. Translated by Saskya Iris Jain. New York: Routledge, 2008 (First published 2004), p. 31.

[17] D. Leatherbarrow, Architecture Oriented Otherwise, p. 53. 